\title{
Estimating time series of land surface energy fluxes using optimized two source energy balance schemes: Model formulation, calibration, and validation
}

\author{
Guojing Gan ${ }^{\mathrm{a}, \mathrm{b}}$, Yanchun Gao ${ }^{\mathrm{a}, *}$ \\ ${ }^{a}$ Key Laboratory of Water Cycle and Related Land Surface Processes, Institute of Geographical Sciences and Natural Resources Research, Chinese Academy \\ of Sciences, P.O. Box 9719, Beijing 100101, China \\ ${ }^{\mathrm{b}}$ University of the Chinese Academy of Sciences, Beijing 100049, China
}

\section{A R T I C L E I N F O}

\section{Article history:}

Received 30 May 2014

Received in revised form 1 April 2015

Accepted 13 April 2015

\section{Keywords:}

Evapotranspiration

TSEB

Canopy conductance

Resistance network

MODIS LST

\begin{abstract}
A B S T R A C T
Due to the limited availability of land surface temperature (LST) images, thermal-based evapotranspiration (ET) models can only provide instantaneous ET snapshots. In contrast, models that are based on near surface soil moisture (SM) and leaf area index (LAI) can operate at daily scales. However, their transpiration schemes need to be more physically realistic and their model parameters usually need to be calibrated by flux measurements. In this study, we incorporated a biophysical canopy conductance (Gc) model into a two source energy balance (TSEB) scheme to replace the original Priestly-Taylor (PT) approximation and then optimized both models (Gc-TSEB and PT-TSEB) at pixel scales using qualified MODIS LST data. The results show that using LST is almost as effective in the calibration as using flux measurements. This is promising because unlike flux measurements, LST can be acquired at various spatial resolutions by remote sensing, which makes model calibration feasible for any land pixel. In addition, ET and its partitioning between the canopy and soil layers were found to be reasonable at both validation sites. The day to day and diurnal variations of the predicted ET generally matched the trends and peaks of the flux measurements, although systematic biases were also found due to the decoupling effect of soil moisture at different depths. Furthermore, both models are robust with $\pm 50 \%$ changes of SM or LAI because the parameters were automatically adjusted by the LST-calibration. The models are sensitive to LST. However, if the added noise of the LST is less significant than $\mathrm{N}\left( \pm 1,2.5^{2}\right)$, the medians of the RMSEs in the LE predictions from the LST-calibrated models were quite similar to those from the flux-calibrated models. Both models were found to be accurate, but Gc-TSEB provides slightly more precise and robust predictions than PT-TSEB.
\end{abstract}

(c) 2015 Elsevier B.V. All rights reserved.

\section{Introduction}

Evapotranspiration (ET), which includes evaporation and plant transpiration, is a crucial hydro-meteorological component that influences water availability and energy partitioning at the land surface. More than $60 \%$ of the land surface precipitation and over half of the solar radiation that are absorbed by the land surface are consumed by ET on annual time scales (Oki and Kanae, 2006; Trenberth et al., 2009, 2007). Quantifying the spatial variability of ET is important for increasing our understanding of the hydrological

\footnotetext{
* Corresponding author. Tel.: +86 01064888991.

E-mail addresses: ganguojing10@gmail.com (G. Gan), gaoyanc@igsnrr.ac.cn (Y. Gao).
}

cycle, ecology system, and water resource management (McCabe and Wood, 2006).

Remote sensing has long been recognized as the most feasible way to estimate land surface ET (usually expressed as its accompanying energy flux, the latent heat flux, which is denoted as LE) over regional and global scales (Kustas and Norman, 1999; Mu et al., 2011). Diagnostic ET models mainly use remotely sensed land surface temperature (LST), near surface soil moisture or leaf area index (LAI) as key boundary conditions to determine LE through surface energy balance equations.

One such diagnostic model that uses LST, the two source energy balance model $\left(\mathrm{TSEB}_{\mathrm{TR}}\right.$ ) that was developed by Norman et al. (1995), has been widely applied to various landscapes (Colaizzi et al., 2012; French et al., 2005) and has been shown to be superior to other thermal-based models (Gao and Long, 2008; Timmermans et al., 2007). Transpiration is estimated in $\mathrm{TSEB}_{\mathrm{TR}}$ through the 
Priestly-Taylor (PT) approach (Priestley and Taylor, 1972) with the coefficient $\left(\alpha_{\mathrm{PT}}\right)$, which is initially set to 1.26 and can be adjusted if the calculated soil evaporation is unrealistic. In addition, studies that incorporate canopy conductance $\left(G_{c}\right)$ models into TSEB schemes have found that $G_{\mathrm{c}}$ models are useful in modeling instantaneous transpiration under various atmospheric and soil moisture conditions if LST is used as a key constraint (Anderson et al., 2008, 2000; Zhan and Kustas, 2001).

TSEB $_{\mathrm{TR}}$ does not require calibration, but the extrapolation of instantaneous LE from TSEB $_{\mathrm{TR}}$ to continuous daily series is still not well understood, especially under cloudy conditions. To address this problem, Kustas et al. $(2001,1998,1999)$ replaced LST with microwave-derived near surface $(0 \sim 5 \mathrm{~cm})$ soil moisture as a key boundary condition within the TSEB framework (denoted as TSEB $_{S M}$ ) to estimate daily ET. Soil evaporation is constrained by the near surface soil moisture through two soil texture-dependent coefficients (Sellers et al., 1992). Although the model performance was found to be sensitive to these two coefficients (Li et al., 2006), no study has provided corresponding values of these coefficients for each type of soil texture. In addition, TSEB $_{S M}$ cannot easily adjust $\alpha_{\text {PT }}$ (Kustas et al., 2003) to accommodate a range of environmental conditions because LST is not included in the model. Modeling transpiration in a more physically realistic way and calibrating the model parameters are necessary before TSEB $_{S M}$ can be widely applied.

In addition to utilizing LST and soil moisture, many studies have also integrated the remotely sensed LAI into the $G_{c}$-based Penman-Monteith (PM) approach (Monteith, 1965; Penman, 1948) to estimate daily ET (Cleugh et al., 2007; Mu et al., 2007). Gc-PM models are usually calibrated at pixel scales by eddy covariance (EC) flux measurements (Leuning et al., 2008) or at catchment scales by runoff measurements (Zhang et al., 2008, 2010). In addition, Yan et al. (2012) used a soil water balance sub-model to scale potential ET from a Gc-PM model to actual ET and thus avoided the need for site-specific parameter calibration.

Calibrating ET models that are based on soil moisture or LAI at pixel scales without in-situ measurements is of great practical significance. Several studies have successfully used ET estimated by thermal-based models to calibrate daily-scale models (Liu, 2012; Long and Singh, 2010). However, it is more intriguing to calibrate model parameters at pixel scales using remotely sensed LST without introducing additional errors other than the uncertainty of the LST itself.

In this study, we incorporated the $G_{c}$ model that was developed by Leuning et al. (2008) into TSEB $_{S M}$ to replace the original PT formulation and evaluated the strength of using the quality-controlled MODIS LST in optimizing resistance networks of the TSEB model (including the Gc version, Gc-TSEB, and the PT version, PT-TSEB). Because LST is an important indicator of the energy balance and thermal state of the land surface, the models are expected to give reasonable energy fluxes when they predict the best LST with the optimized parameters. The calibrated models were used to calculate energy fluxes at a half hourly resolution without remotely sensed LST data. EC flux measurements and predictions from models that were calibrated by flux data were used as references to evaluate the LST-calibrated models at half hour and daytime scales. We also performed sensitivity analyses to test the robustness of both models with $\pm 50 \%$ changes of LAI or near surface soil moisture as well as a series of assumed uncertainties of the LST itself.

\section{Resistance networks of the models}

A resistance network links the instantaneous surface state (LST and soil moisture) to the energy fluxes. In this section, we provide a detailed description of the models' resistance networks (Fig. 1),

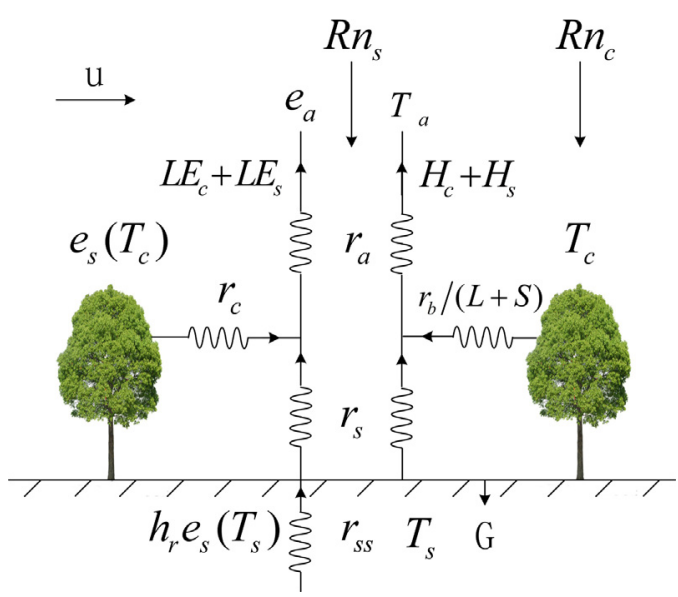

Fig. 1. Resistance network of the model.

in which most of the components are adopted from the original TSEB model (Kustas et al., 1998; Norman et al., 1995), and some are updated by recent studies from the literature.

The term $r_{\mathrm{a}}\left(z_{\mathrm{h}}\right)$ represents the aerodynamic resistance, which is estimated from the wind speed and surface roughness (Li et al., 2005). The canopy conductance $\left(G_{c}\right)$ is modeled as a function of the LAI, water vapor deficit $\left(D_{\mathrm{a}}\right)$, and visible radiation $\left(Q_{\mathrm{h}}\right)$ (Leuning et al., 2008).

$G_{\mathrm{c}}=\frac{g_{\mathrm{sx}}}{k_{\mathrm{Q}}} \ln \left[\frac{Q_{\mathrm{h}}+Q_{50}}{Q_{\mathrm{h}} \exp \left(-k_{\mathrm{Q}} L A I\right)+Q_{50}}\right]\left[\frac{1}{1+D_{\mathrm{a}} / D_{50}}\right]$

where $g_{s x}$ is the maximum stomatal conductance, $k_{\mathrm{Q}}$ is the extinction coefficient for shortwave radiation, $Q_{50}$ and $D_{50}$ are the visible radiation and the humidity deficit, respectively, when the stomatal conductance is half of its maximum. $g_{s x}, k_{\mathrm{Q}}, Q_{50}$, and $D_{50}$ are the parameters to be calibrated. The canopy resistance $\left(r_{\mathrm{c}}\right)$ is the reciprocal of the canopy conductance.

$r_{\mathrm{c}}=\frac{1}{G_{\mathrm{c}}}$

The leaf boundary layer resistance $\left(r_{\mathrm{b}}\right)$ represents the resistance exerted by leaves on the canopy heat fluxes and is formulated as in the Community Land Model (Oleson et al., 2010).

$r_{\mathrm{b}}=\frac{20}{\sqrt{u_{*}}}$

where $u^{*}$ is the friction velocity, which represents the surface shear stress. $L$ and $S$ (Fig. 1 ) are the LAI and stem area index, respectively.

The resistance to sensible and latent heat fluxes between the soil surface and the canopy displacement height (under-canopy resistance, $r_{\mathrm{s}}$ ) is formulated as in the Community Land Model (Zeng et al., 2005 ) instead of the original formulation in TSEB.

$r_{\mathrm{s}}=\frac{1}{\left(c_{\mathrm{s}} u_{*}\right)}$

where $c_{\mathrm{s}}$ is the turbulent transfer coefficient, which is obtained by the interpolation between the values for the bare soil and dense canopy (Zeng et al., 2005).

$c_{\mathrm{s}}=c_{\mathrm{s}, \text { bare }} w_{\mathrm{s}}+c_{\mathrm{s}, \text { dense }}\left(1-w_{\mathrm{s}}\right)$

$c_{\mathrm{s}, \text { bare }}=\frac{k}{a}\left(\frac{z_{0 \mathrm{~m}, \mathrm{~g}} u_{*}}{v}\right)^{-0.45}$

where $z_{0 \mathrm{~m}, \mathrm{~g}}$ is the ground momentum roughness length, which is taken as $0.01 \mathrm{~m} ; v=1.5 \times 10^{-5} \mathrm{~m}^{2} \mathrm{~s}^{-1}$ is the kinematic viscosity of air, $a=0.13$, and $c_{\mathrm{s} \text {, dense }}$ is taken as 0.004 (Zeng et al., 2005). 
The formulation of the empirical interpolation weight, $w_{\mathrm{s}}$, must satisfy the criteria that $c_{\mathrm{s}}$ approaches $c_{\mathrm{s}}$, bare when there is no vegetation and approaches $c_{\mathrm{s}}$, dense when the vegetation is dense. $w_{\mathrm{s}}$ was empirically defined as $e^{-(L+S)}$ in Zeng et al. (2005) and accounts for the impacts of the leaf and stem areas of the canopy on $c_{s}$. Note that $u^{*}$ only represents the shear stress on the canopy top, so the canopy height should be included in the formulation of $c_{s}$. We formulated the interpolation weight as $e^{-L-\Omega h_{c}}$ to account for the effects of both LAI and canopy height on $c_{s}$. The stem area index is related to the canopy height, so its impact is included in $\Omega$, which is a parameter to be calibrated.

The original TSEB model calculates $r_{\mathrm{s}}$ according to the attenuating effects of vegetation on wind speed ( $u_{\mathrm{s}}$, typically at $0.05-0.2 \mathrm{~m}$ ) inside the canopy (Eq. (7)). Norman et al. (1995) suggested that as the vegetation becomes sparse, the calculation of $u_{\mathrm{s}}$ through exponential wind profile should be modified to be larger; however, it is unclear when and how to adjust $u_{\mathrm{s}}$ when the vegetation fraction tends to be 0 . As a result, although no study (to our knowledge) has shown that the formulation of Zeng et al. (2005) is more accurate than that of Eq. (7), we use it because they provide convergent $r_{s}$ estimates as the vegetation cover varies from 1 to 0 . Such consistency is important because our study period covers all of the growing stages of the corn at the crop site, and the grass at the grass site remains approximately only $0.05 \mathrm{~m}$ high for most of the period.

$r_{\mathrm{s}}=\frac{1}{a+b u_{\mathrm{s}}}$

The surface soil resistance $\left(r_{s s}\right)$ to latent heat transfer is estimated by an exponential function of the near surface soil moisture (Sellers et al., 1992).

$r_{\mathrm{ss}}=\exp \left(a_{0}-a_{1} \frac{w}{w_{\text {sat }}}\right)$

where $w$ is the near surface soil moisture content (volumetric content) and $w_{\text {sat }}$ is the saturated soil moisture content. The coefficients $a_{0}$ and $a_{1}$, which were taken as 8.2 and 4.3 , respectively, in previous studies (Kustas et al., 1998; Sellers et al., 1992), will be calibrated in this study.

The soil heat flux $(G)$ is estimated as a constant part of the net radiation of the soil layer $\left(R n_{\mathrm{S}}\right)$. The unknown ratio $\alpha_{\mathrm{G}}$ represents the ability of the soil to conduct heat flow and requires calibration.

$G=\alpha_{\mathrm{G}} R n_{\mathrm{s}}$

\section{Calculation and calibration procedures}

The models are based on the surface energy balance between the net radiation and heat fluxes. To determine the net radiation, we need to know LST. The net radiation is partitioned between the canopy and soil layers. The LST components and heat fluxes in both layers can be uniquely determined through energy balance equations. In this way, the LST and net radiation are coupled; once they are solved by iteration, the heat fluxes are simultaneously determined.

The step by step calculation procedures (Fig. 2) are explained below. All of the resistance terms are described in Section 2. Subscripts $\mathrm{c}$ and s indicate the canopy and soil layers, respectively.

1) Initiate the LST as air temperature $\left(T_{\mathrm{a}}\right)$.

2) Compute the net radiation $\left(R_{\mathrm{n}}\right)$ of the land surface and determine its partitioning between the canopy and soil layers.

$R_{\mathrm{n}}=(1-\alpha) R_{\mathrm{S}} \downarrow+\epsilon_{\mathrm{S}} R_{\mathrm{l}} \downarrow-\epsilon_{\mathrm{S}} \sigma \mathrm{LST}^{4}$

where $R_{\mathrm{s}} \downarrow$ and $R_{\mathrm{l}} \downarrow$ are the incoming short wave and long wave radiation, respectively. $\alpha$ and $\epsilon_{\mathrm{s}}$ are the land surface albedo and

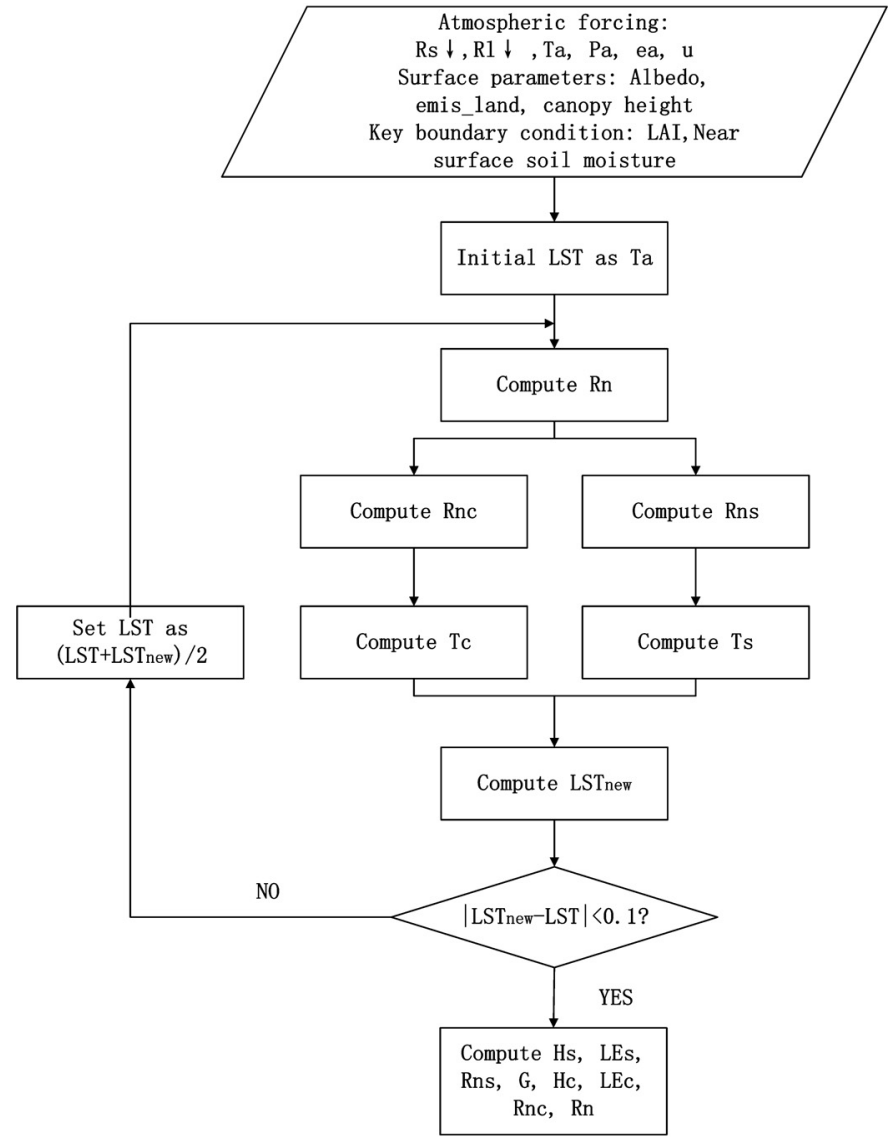

Fig. 2. Flow chart of the calculation procedure.

emissivity, respectively, and $\sigma$ is the Stefan-Bolzmann constant $\left(5.67 \times 10^{-8} \mathrm{Wm}^{-2} \mathrm{~K}^{-4}\right)$.

The net radiation is partitioned through an exponential function (Anderson et al., 1997) of the LAI, solar zenith angle $\left(\theta_{\mathrm{S}}\right)$ and extinction coefficient $(\kappa)$ (Norman et al., 2000).

$R n_{\mathrm{c}}=R n\left\{1-\exp \left[-\kappa L A I / \sqrt{2 \cos \left(\theta_{\mathrm{s}}\right)}\right]\right\}$

$R n_{\mathrm{s}}=R n \exp \left[-\kappa L A I / \sqrt{2 \cos \left(\theta_{\mathrm{s}}\right)}\right]$

3) Compute the component temperatures by solving the corresponding energy balance equations. The net radiation is balanced by the sensible and latent heat fluxes in the canopy layer.

$\mathrm{H}_{\mathrm{C}}+\mathrm{LE}_{\mathrm{C}}=R n_{\mathrm{C}}$

$\mathrm{H}_{\mathrm{c}}=\rho c_{\mathrm{p}} \frac{T_{\mathrm{c}}-T_{\mathrm{a}}}{r_{\mathrm{a}}+r_{\mathrm{b}} /(L+S)}$

$\mathrm{LE}_{\mathrm{c}}=\frac{\rho c_{\mathrm{p}}}{\gamma} \frac{e_{\mathrm{s}}\left(T_{\mathrm{c}}\right)-e_{\mathrm{a}}}{r_{\mathrm{a}}+r_{\mathrm{c}}}$

$\mathrm{LE}_{\mathrm{c}}=\alpha_{\mathrm{PT}} \frac{\Delta}{\Delta+\gamma} R n_{\mathrm{c}}$

where $\rho$ is the air density $\left(1.25 \mathrm{~kg} / \mathrm{m}^{3}\right), c_{\mathrm{p}}$ is the specific heat of air $(1005 \mathrm{~J} / \mathrm{kg} / \mathrm{K})$ at a constant pressure, $\gamma$ is the psychrometric constant $(0.667 \mathrm{hpa} / \mathrm{K}), \Delta$ is the slope of the saturated vapor pressure to the air temperature, and $e_{\mathrm{S}}\left(T_{\mathrm{C}}\right)$ is the saturated vapor pressure at temperature $T_{\mathrm{c}}$.

A nonlinear equation with only one unknown variable $\left(T_{\mathrm{C}}\right)$ can be derived from Eqs. (13), (14), and (15) for Gc-TSEB. The 
equation can be solved using the Newton-Raphson iteration approach. The existence and uniqueness of the solution are guaranteed by the monotonically increasing property of the function $\mathrm{F}\left(T_{\mathrm{c}}\right)=H_{\mathrm{c}}+\mathrm{LE}_{\mathrm{c}}-R n_{\mathrm{c}}$. Similarly, $T_{\mathrm{c}}$ can be derived from Eqs. (13), (14), and (16) for PT-TSEB.

For the soil layer, the net radiation is partitioned between the sensible heat flux, latent heat flux, and soil heat flux. Similarly, a unique solution for the soil temperature can also be achieved through Newton-Raphson iteration using Eqs. (9) and (17)-(20).

$$
\begin{aligned}
& \mathrm{H}_{\mathrm{s}}+\mathrm{LE}_{\mathrm{s}}+G=R n_{\mathrm{s}} \\
& \mathrm{H}_{\mathrm{s}}=\rho c_{\mathrm{p}} \frac{T_{\mathrm{s}}-T_{\mathrm{a}}}{r_{\mathrm{a}}+r_{\mathrm{s}}} \\
& \mathrm{LE}_{\mathrm{s}}=\frac{\rho c_{\mathrm{p}}}{\gamma} \frac{h_{\mathrm{r}} e_{\mathrm{s}}\left(T_{\mathrm{s}}\right)-e_{\mathrm{a}}}{r_{\mathrm{a}}+r_{\mathrm{s}}+r_{\mathrm{ss}}}
\end{aligned}
$$

where $h_{\mathrm{r}}$ is the relative humidity of the air adjacent to the soil water (Camillo and Gurney, 1986), and $e_{S}\left(T_{S}\right)$ is the saturated vapor pressure at temperature $T_{\mathrm{s}}$.

4) Determine the new LST (denoted as LST $_{\text {new }}$ ) as the composite of $T_{\mathrm{C}}$ and $T_{\mathrm{S}}$ in step 3 using the vegetated fraction as the interpolation weight (Norman et al., 1995).

$\mathrm{LST}_{\text {new }}=\left[f_{\mathrm{c}} T_{\mathrm{c}}{ }^{4}+\left(1-f_{\mathrm{c}}\right) T_{\mathrm{s}}{ }^{4}\right]^{1 / 4}$

$f_{\mathrm{c}}=1-\exp (-0.5 \mathrm{LAI})$

5) Set LST as $\left(\mathrm{LST}+\mathrm{LST}_{\text {new }}\right) / 2$ if $\left|\mathrm{LST}_{\text {new }}-\mathrm{LST}\right|$ is larger than the given threshold (taken as $0.1 \mathrm{~K}$ in this study) and then repeat step 2 ; otherwise, the iteration procedure ends. When the iteration ends, the LST and energy fluxes are those from steps 4 and 3, respectively.

We use the quality-controlled MODIS LST as LST act to calibrate the model parameters. The penalty function is defined as the root mean square error (RMSE) of the modeled LST. The simulated annealing technique (Dekkers and Aarts, 1991; Kirkpatrick et al., 1983 ) is used to search for the optimized set of parameters in the parameter space to minimize the penalty function. The simulated annealing technique can achieve global optima by the so called hillclimbing moves to avoid being trapped in local minima. Models that are calibrated by flux measurements are also used as references to evaluate the performances of the models that are calibrated by the LST. In the flux calibration mode, the penalty function is defined as the sum of the RMSEs of the modeled $H$ and LE.

The ranges for the parameters are set as follows: $\alpha_{\mathrm{PT}}: 0.5-2, g_{\mathrm{sx}}$ : $0.002-0.15 \mathrm{~m} / \mathrm{s}, Q_{50}: 20-50 \mathrm{~W} / \mathrm{m}^{2}, D_{50}: 0.7-1.5 \mathrm{kPa}, k_{\mathrm{Q}}: 0.3-1.0, a_{0}$ : $5-15, a_{1}: 0-15, \Omega:-10$ to $2, \alpha_{\mathrm{G}}: 0.15-0.35$. At the same time, on average, the maximum values of $g_{s x}$, together with $Q_{50}, D_{50}$, and $k_{\mathrm{Q}}$, must result in a corresponding $\alpha_{\mathrm{PT}}$ value of not larger than 2 . To avoid over-tuning the parameters, we further constrain $\Omega$ under the principle that, on average, the effect of $\Omega\left(\left|\Omega^{*} h_{\mathrm{c}}\right|\right)$ will not exceed that of the LAI in the formulation of $r_{\mathrm{s}}$.

\section{Study site description and data preprocessing}

To run the models and evaluate their performances, we downloaded the in-situ measurement data of the TongYu station from the Coordinated Energy and Water Cycle Observations Project (CEOP) reference site data archive (http://www.ceop.net/) and the MODIS products from the Goddard Space Flight Center (http://ladsweb.nascom.nasa.gov/data/). The data that were used in this study are summarized in Table 1 . In this section, we briefly describe the TongYu station, the processing of the flux data, and the construction of the calibration and validation datasets.
TongYu station, which contains two identical observation systems at a crop site $\left(44.5921^{\circ} \mathrm{N}, 122.8773^{\circ} \mathrm{E}\right)$ and a grass site $\left(44.5672^{\circ} \mathrm{N}, 122.9298^{\circ} \mathrm{E}\right)$, is located on the SongNen plain, which is one of the most important areas of grain production in China. The annual mean air temperature at TongYu station is $5.2^{\circ} \mathrm{C}$, and the annual mean precipitation is $404.3 \mathrm{~mm}$. Corn is planted at the crop site and reaches its maximum height $(\sim 1.8 \mathrm{~m})$ in September. Short grass grows at the grass site and remains less than $0.1 \mathrm{~m}$ high for the entire year (Tu, 2007). The different land covers at Tongyu station provide good opportunities to evaluate the models.

All of the in-situ measurements were recorded at an interval of $30 \mathrm{~min}$ and represent either instantaneous measurements or 30 -min averages prior to the recorded observation time (Table 1). The EC systems measured fluxes at the spatial scale of the MODIS LST (approximately $0.01^{\circ}$ ) because the station is surrounded by homogeneous flat terrain and is not sheltered by tall obstacles. Closure corrections must be performed on the sensible and latent heat fluxes from the EC systems before the flux measurements can be used. In addition, to work with satellite products, the flux measurements should be interpolated to instantaneous values. We partitioned the instantaneous available energy during the satellite passage between the sensible and latent heat fluxes based on the 30-min average evaporative fraction that was measured by the EC system (Twine et al., 2000).

Soil heat flux measurements below the surface are not comparable to the model-predicted surface values. We used the calorimetric method (Heusinkveld et al., 2004) to estimate the soil heat flux at the surface by combining the heat storage in the top $0.05 \mathrm{~m}$ soil layer and the soil heat flux at $0.05 \mathrm{~m}$ below the surface. The near surface soil moisture was derived from in-situ measurements instead of microwave retrievals because microwave measurements provide soil moisture estimates at a coarser temporal resolution (polar satellite passes near noon every day) than the 30 -min scale that was used in this study. In addition, the rationality of estimating the near surface soil moisture at pixel scales using point measurements will be discussed in Section 5.2.

For each site, we first construct a data set for model calibration. We cover a time period from DOY 180 to DOY 270 in 2003 and 2004 during which the corn fields were in the growing period. The calibration data are taken from the time when the highest quality MOD11L2/MYD11L2 LST data are available. The calibration data set includes remotely sensed products, atmospheric forcing, soil moisture, and energy flux measurements at these timings. Second, the validation data set includes the same type of inputs except for LST but covers different timings. The model inputs at a 30 -min scale from 8:30 to 17:30 (local time) during the entire study period are used for the model evaluation.

\section{Results and discussion}

\subsection{Model calibration and validation}

Overall, using LST is almost as effective as using the flux measurements in calibrating the model parameters (see Table 2). The Gc-TSEB model-estimated $H$ and LE had similar accuracies compared with the observations using both calibration modes (Table 3, Fig. 3), whereas the LST-calibrated PT-TSEB (denoted as PTTSEB $_{\text {LST }}$ ) had slightly higher discrepancies with the observed fluxes compared to the PT-TSEB that was calibrated using the flux measurements (Table 3). In contrast, the PT-TSEB without calibration significantly overestimated the observed LE.

The PT-TSEB model algorithm in this study used a different resistance network formulation from the original TSEB $_{S M}$ model developed by Kustas et al. (1998). Therefore, the significant overestimation in LE in applying the non-calibrated PT-TSEB model is 
Table 1

Summary of the data used in this study.

\begin{tabular}{|c|c|c|c|c|}
\hline Data & Measurements & Height & Inst/Aver ${ }^{\mathrm{a}}$ & Usage \\
\hline Forcings & $\begin{array}{l}\text { Incoming radiation } \\
\text { Air temperature } \\
\text { Specific humidity } \\
\text { Air pressure } \\
\text { Wind speed }\end{array}$ & $\begin{array}{l}3 \mathrm{~m} \\
3.95 \mathrm{~m} \\
3.95 \mathrm{~m} \\
1.5 \mathrm{~m} \\
17.06 \mathrm{~m}\end{array}$ & $\begin{array}{l}\text { Inst } \\
\text { Inst } \\
\text { Inst } \\
\text { Aver } \\
\text { Aver }\end{array}$ & $\begin{array}{l}R_{\mathrm{s}} \downarrow, R_{\mathrm{l}} \downarrow \\
T_{\mathrm{a}} \\
\text { Estimate } e_{\mathrm{a}} \\
P_{\mathrm{a}} \\
u\end{array}$ \\
\hline $\begin{array}{l}\text { Subsurface } \\
\text { measurements }\end{array}$ & $\begin{array}{l}\text { Soil temperature } \\
\text { Soil moisture }\end{array}$ & $\begin{array}{l}-0.02 \mathrm{~m} \\
-0.05 \mathrm{~m}\end{array}$ & $\begin{array}{l}\text { Inst } \\
\text { Inst }\end{array}$ & $\begin{array}{l}\text { Estimate } G \\
w\end{array}$ \\
\hline Flux measurements & $\begin{array}{l}\text { Sensible heat fluxes } \\
\text { latent heat fluxes } \\
\text { Soil heat flux }\end{array}$ & $\begin{array}{l}3.5 \mathrm{~m}^{\mathrm{b}} \\
3.5 \mathrm{~m}^{\mathrm{b}} \\
-0.05 \mathrm{~m}\end{array}$ & $\begin{array}{l}\text { Aver } \\
\text { Aver } \\
\text { Aver }\end{array}$ & $\begin{array}{l}H \\
\text { LE } \\
\text { Estimate } G\end{array}$ \\
\hline MODIS products & $\begin{array}{l}\text { MOD11L2/MYD11L2 } \\
\text { MOD15A2 } \\
\text { MCD43B3 }\end{array}$ & ---- & $\begin{array}{l}\text { Inst } \\
\text { Inst } \\
\text { Inst }\end{array}$ & $\begin{array}{l}\text { LST } \\
\text { LAI } \\
\text { albedo }\end{array}$ \\
\hline
\end{tabular}

a Inst stands for instantaneous. Aver stands for average.

b The measurement height for $H$ and $L E$ at the grass site was $2.0 \mathrm{~m}$.

Table 2

Parameters calibrated by LST or EC measurements at the crop site and the grass site, respectively.

\begin{tabular}{|c|c|c|c|c|c|c|c|c|}
\hline Gc-TSEB & $\begin{array}{l}g_{\mathrm{sx}} \\
(\mathrm{m} / \mathrm{s})\end{array}$ & $\begin{array}{l}Q_{50} \\
\left(\mathrm{~W} / \mathrm{m}^{2}\right)\end{array}$ & $\begin{array}{l}D_{50} \\
(\mathrm{kPa})\end{array}$ & $k_{\mathrm{Q}}$ & $a_{0}$ & $a_{1}$ & $\Omega$ & $\alpha_{\mathrm{G}}$ \\
\hline Crop, LST & 0.013 & 29.9 & 0.95 & 0.50 & 15.0 & 12.4 & 0.68 & 0.20 \\
\hline Crop, $H+$ LE & 0.013 & 21.7 & 0.94 & 0.69 & 12.0 & 8.3 & 0.27 & 0.30 \\
\hline Grass, LST & 0.044 & 20.3 & 0.71 & 0.31 & 13.4 & 9.2 & -6.38 & 0.35 \\
\hline Grass, $H+\mathrm{LE}$ & 0.022 & 27.9 & 0.77 & 0.72 & 7.3 & 0.7 & -3.54 & 0.35 \\
\hline PT-TSEB & $\alpha_{\mathrm{PT}}$ & & & & $a_{0}$ & $a_{1}$ & $\Omega$ & $\alpha_{\mathrm{G}}$ \\
\hline Crop, LST & 1.027 & & & & 14.4 & 11.7 & 0.58 & 0.15 \\
\hline Crop, $H+$ LE & 1.079 & & & & 15.0 & 11.5 & 1.01 & 0.19 \\
\hline Grass, LST & 1.210 & & & & 11.9 & 7.5 & -7.47 & 0.34 \\
\hline Grass, $H+$ LE & 1.137 & & & & 7.5 & 0.6 & -4.96 & 0.35 \\
\hline
\end{tabular}

Table 3

RMSEs and biases of the model predictions during the validation period at the crop site and the grass site.

\begin{tabular}{|c|c|c|c|c|c|c|c|c|c|c|}
\hline & \multicolumn{2}{|c|}{ LST(K) ${ }^{\mathrm{a}}$} & \multicolumn{2}{|c|}{$R_{\mathrm{n}}\left(\mathrm{W} / \mathrm{m}^{2}\right)$} & \multicolumn{2}{|c|}{$H\left(\mathrm{~W} / \mathrm{m}^{2}\right)$} & \multicolumn{2}{|c|}{$\mathrm{LE}\left(\mathrm{W} / \mathrm{m}^{2}\right)$} & \multicolumn{2}{|c|}{$G\left(\mathrm{~W} / \mathrm{m}^{2}\right)$} \\
\hline & RMSE & BIAS & RMSE & BIAS & RMSE & BIAS & RMSE & BIAS & RMSE & BIAS \\
\hline \multicolumn{11}{|l|}{ GC-TSEB } \\
\hline Crop, LST & 2.71 & 0.13 & 30 & 20.8 & 44.8 & 11.4 & 67.8 & 1.4 & 26.5 & 8.0 \\
\hline Crop, $H+$ LE & 3.89 & -2.65 & 39.6 & 31.1 & 41.7 & -0.6 & 68.9 & 6.4 & 40.5 & 25.3 \\
\hline Grass, LST & 3 & 0.39 & 27.3 & 18.6 & 39.1 & -0.9 & 57.3 & -5.8 & 34.6 & 25.4 \\
\hline Grass, $H+$ LE & 3.34 & -0.03 & 30.8 & 21.3 & 37.5 & -1.2 & 56.5 & -2.8 & 35.4 & 25.3 \\
\hline \multicolumn{11}{|l|}{ PT-TSEB } \\
\hline Crop, LST & 2.69 & -0.28 & 30 & 20.9 & 44.6 & 26.3 & 54.3 & -6.7 & 23.4 & 1.24 \\
\hline Crop, $H+$ LE & 4.4 & 2.97 & 23.2 & 8.8 & 39.4 & 16.1 & 54.3 & -13.6 & 25.5 & 6.3 \\
\hline Crop, $\mathrm{NC}^{\mathrm{b}}$ & & & 50.1 & 40.9 & 84.7 & -61.1 & 108.6 & 75 & 42.1 & 27.0 \\
\hline Grass, LST & 3 & 0.21 & 48.2 & 40.2 & 52.1 & 22.5 & 61.1 & -8.6 & 37.5 & 26.3 \\
\hline Grass, $H+\mathrm{LE}$ & 3.3 & 0.19 & 32.6 & 24.2 & 36.7 & 12.3 & 51.3 & -11.8 & 35.3 & 23.7 \\
\hline Grass, NC & & & 47.5 & 39.5 & 63.4 & -27.1 & 93.9 & 49.3 & 29.8 & 17.3 \\
\hline
\end{tabular}

a LST was evaluated during the calibration period.

b NC stands for no calibration.

not indicative of the results that would have been obtained using the original TSEB $\mathrm{SM}_{\mathrm{M}}$ model formulation. In addition, because the $\mathrm{LE}_{\mathrm{c}}$ that was estimated with $\alpha_{\mathrm{PT}}$ taken as 1.26 resulted in relatively small differences from the flux-calibrated PT-TSEB (averages of $\sim 20 \mathrm{~W} / \mathrm{m}^{2}$ and $10 \mathrm{~W} / \mathrm{m}^{2}$ at the crop and grass sites, respectively), the 1.26 initial value for $\alpha_{\mathrm{PT}}$ was a reasonable value to adopt. In contrast, the overestimation in $\mathrm{LE}_{\mathrm{s}}$ from applying the non-calibrated PT-TSEB exceeded $50 \mathrm{~W} / \mathrm{m}^{2}$ at both sites compared with the PTTSEB that was calibrated using the flux measurements, suggesting that the soil evaporation had been overestimated.

In contrast, the LE components from the LST-calibrated models were generally found to be highly correlated with their counterparts from the flux-calibrated models, and a maximum average trade-off of only $23 \mathrm{~W} / \mathrm{m}^{2}$ between $\mathrm{LE}_{\mathrm{c}}$ and $\mathrm{LE}_{\mathrm{s}}$ was found when Gc-TSEB was applied at the grass site (Table 4). The LST calibration mode ended up with a reasonable $\mathrm{LE}_{\mathrm{c}} / \mathrm{LE}_{\mathrm{s}}$ partitioning, which is not surprising. During the calibration period, if LE is completely taken up by $\mathrm{LE}_{\mathrm{s}}\left(\mathrm{LE}_{\mathrm{c}}\right)$ when $f_{\mathrm{c}}$ is small, then the estimation of LST will be positively (negatively) biased when $f_{\mathrm{c}}$ is large because the transpiration will be too small (large). It is therefore expected that the LST calibration mode will work well if the calibration period covers the full range of $f_{\mathrm{c}}$. This is promising because the partitioning of ET into evaporation and transpiration is important for assessing biomass production and the allocation of increasingly scarce water resources (Kool et al., 2014). As a comparison, the original TSEB $\mathrm{TR}_{\mathrm{TR}}$ and TSEB $\mathrm{SM}_{\mathrm{M}}$ cannot adjust $\alpha_{\mathrm{PT}}$ down unless the $\mathrm{LE}_{\mathrm{S}}=0$ threshold is 

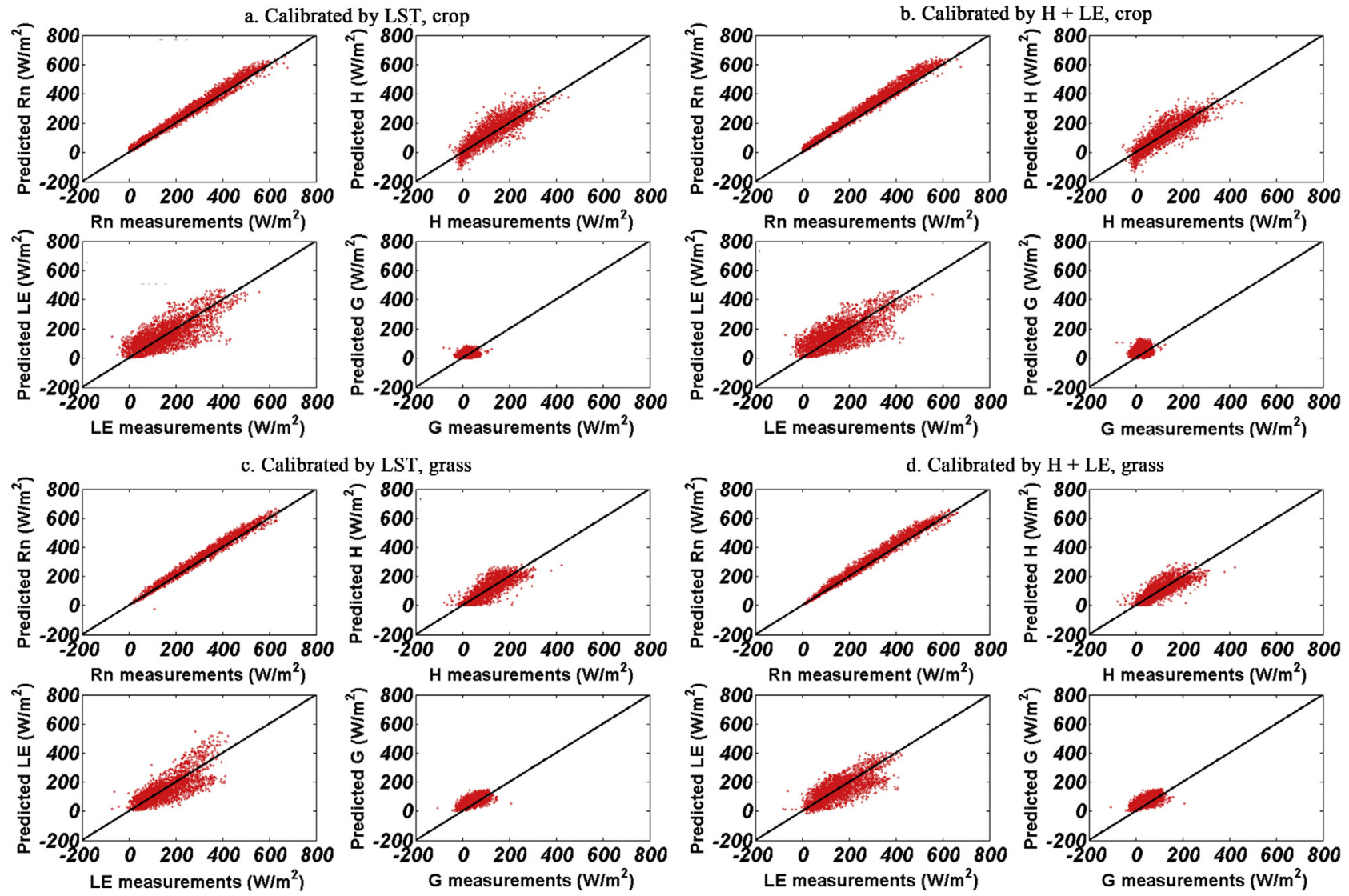

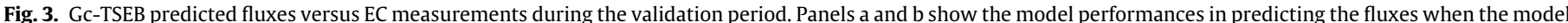

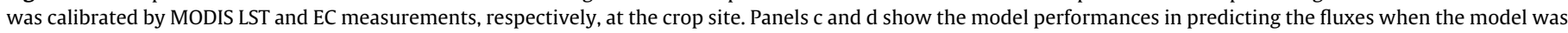
calibrated by MODIS LST and EC measurements, respectively, at the grass site.

reached (Anderson et al., 2008), which usually results in overestimates of $\mathrm{LE}_{\mathrm{c}}$.

It should be noted that other factor in addition to the model parameters may cause errors in the $\mathrm{LE}_{\mathrm{c}}$ and $\mathrm{LE}_{\mathrm{s}}$ estimations in both models. For example, biases in the albedo may cause biases in $R_{\mathrm{n}}$ (Table 3 ), and the partitioning of $R_{\mathrm{n}}$ between the canopy and soil layers did not consider the difference between the divergences of the short and long wave radiations, which may cause biases in the $\mathrm{LE}_{\mathrm{c}}$ and $\mathrm{LE}_{\mathrm{s}}$ estimations.

The potential for using LST to solve the bulk surface resistance directly from energy balance equations (Boegh et al., 2002) or to optimize the resistance parameters in $\mathrm{TSEB}_{\mathrm{SM}}$ has long been recognized. For example, Li et al. (2006) optimized $a_{0}$ and $a_{1}$ to reduce

Table 4

$L E$ partitioning between the canopy and soil layers.

\begin{tabular}{|c|c|c|c|c|c|c|c|c|}
\hline & \multicolumn{4}{|l|}{$\mathrm{LE}_{\mathrm{c}}$} & \multicolumn{4}{|l|}{$\mathrm{LE}_{\mathrm{s}}$} \\
\hline & Min & Max & Mean & $r^{\mathrm{a}}$ & Min & Max & Mean & $r$ \\
\hline \multicolumn{9}{|l|}{ Crop } \\
\hline $\mathrm{Gc}_{\mathrm{LST}}$ & 2.5 & 357.6 & 124.9 & 0.99 & 0.01 & 162.6 & 28.9 & 0.98 \\
\hline $\mathrm{Gc}_{\text {flux }}$ & 3.1 & 357.7 & 127.9 & & -0.05 & 146.7 & 30.9 & \\
\hline $\mathrm{PT}_{\mathrm{LST}}$ & 0.9 & 341.2 & 116.1 & 0.99 & 0.01 & 171.6 & 30.8 & 0.99 \\
\hline $\mathrm{PT}_{\text {flux }}$ & 0.8 & 353.3 & 117.2 & & 0.01 & 143.8 & 22.6 & \\
\hline \multicolumn{9}{|l|}{ Grass } \\
\hline $\mathrm{Gc}_{\mathrm{LST}}$ & 1.5 & 370.7 & 125.9 & 0.99 & -0.4 & 212.3 & 17.7 & 0.45 \\
\hline $\mathrm{Gc}_{\text {flux }}$ & 3.3 & 317.6 & 103.9 & & -24.6 & 115.3 & 40.0 & \\
\hline $\mathrm{PT}_{\mathrm{LST}}$ & -0.3 & 370 & 113.1 & 0.99 & -1.2 & 371.2 & 20.2 & 0.41 \\
\hline $\mathrm{PT}_{\text {flux }}$ & -0.1 & 336.8 & 102.5 & & -19 & 82.8 & 27.6 & \\
\hline
\end{tabular}

a $r$ stands for the correlation coefficient between the predictions from models that were calibrated using the LST and fluxes. the LST and $H$ biases and found that factors other than $a_{0}$ and $a_{1}$ may be responsible for the model-measurement discrepancies. As a result, although different datasets and model structures were used, the successful use of remotely sensed LST for the calibration in this study indicated that it may be appropriate for the resistance parameters that are related to both the canopy and soil layers to be adjusted together to account for the bias of the predicted LST.

For example, the calibrated ratio $\alpha_{\mathrm{G}}$ in this study resulted in well-constrained RMSEs and biases of $G$ for both models, especially at the crop site. In addition, at the crop site $\left(h_{\mathrm{c}} \approx 1.5 \mathrm{~m}\right)$, because of the larger $\Omega$ from calibration, the under-canopy resistance would also be larger than that at the grass site $\left(h_{\mathrm{c}} \approx 0.05 \mathrm{~m}\right)$ under the same LAI and canopy top sheer stress conditions, which represents the effect of increasing plant height on $r_{\mathrm{s}}$ (Eqs. (4) and (5)). The automatic adjustments of $\Omega$ at the two sites indicated that our modification of the interpolation weight $\left(w_{s}\right)$ of the turbulent transfer coefficient is reasonable and that the calibration procedure provides insights into the heat transfer process rather than just tuning the parameters to fit the observation data, although we do not define a unique set of parameters for natural land covers.

As mentioned in Section 2, it is important to treat $r_{\mathrm{s}}$ in a consistent way for vegetated surfaces with vegetation covers ranging from 1 to 0. For example, Sanchez et al. (2008) modified the original TSEB $_{\text {TR }}$ model into a "patch" version such that the wind profile in the air space is not related to the vegetation cover or canopy height. This patch version of the TSEB is quite different from the parallel formulation used in this study in both the resistance network and energy flux computation, but future work will test its usefulness of incorporating the canopy conductance in clumped vegetation situations. 



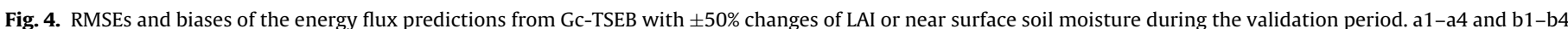

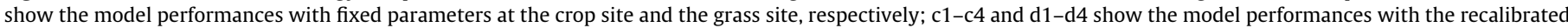
parameters at the crop site and the grass site, respectively.

\subsection{Sensitivity analysis of model performances}

In this section, we will analyze the models' sensitivities to the LAI, near surface soil moisture and LST because the construction and calibration of the models' resistance networks are mainly based on these three variables.

During the study period, the LAI at the crop (grass) site ranged from $0.4(0.3)$ to 2.8 (1.6) with a mean of $1.11(0.68)$, and the near surface soil moisture (volumetric content) ranged from $13.4 \%$ (8.8\%) to $36.7 \%(42.8 \%)$ with a mean of $22 \%$ ( $15.2 \%)$. We set the changes of these two variables to range from $-50 \%$ to $50 \%$ at an interval of $10 \%$. Two different sensitivity analyses are provided for the LAI and soil moisture. First, we ran the model with the changed values of LAI or near surface soil moisture with a fixed set of parameters that were calibrated by the LST with the original input data. In the second way, we calibrated the model parameters against LST every time the LAI or near surface soil moisture was changed. The recalibrated models were then used to calculate the energy fluxes.

Both models are sensitive to the LAI and near surface soil moisture. At both sites, the LAI and near surface soil moisture had positive impacts on LE when the models were run with the fixed parameters, and the magnitude of the impacts can be greater than $80 \mathrm{~W} / \mathrm{m}^{2}$ and $60 \mathrm{~W} / \mathrm{m}^{2}$ at the crop and grass sites, respectively (Figs. 4 and 5. a3 and a 4 and b3 and b4). The RMSE curves of $H$ and LE both had concave shapes and generally increased with the amplitude of the input variation (Figs. 4 and 5. a1 and a2 and b1 and b2). The sensitivity analysis indicates that both models are able to reflect the LE variations under heterogeneous LAI and soil moisture conditions.
For the recalibrated Gc-TSEB, no obvious trend of $H$ and LE biases (except for the bias of $H$ at the grass site with changing LAI) was observed with the change of LAI or near surface soil moisture, and the RMSEs of all of the flux predictions from Gc-TSEB remained nearly constant (Fig. 4. c1-c4 and d1-d4). In addition, at both sites, the absolute values of the biases of $H$ and LE were always smaller than the corresponding $R_{\mathrm{n}}$ biases (nearly constant at $\sim 20 \mathrm{~W} / \mathrm{m}^{2}$ ), except that the bias of $H$ at the crop site $\left(30.5 \mathrm{~W} / \mathrm{m}^{2}\right)$ was slightly larger than the $R_{\mathrm{n}}$ bias $\left(21.2 \mathrm{~W} / \mathrm{m}^{2}\right)$ when the near surface soil moisture was decreased by $50 \%$. This indicates that the uncertainties of the predictions could be constrained when the Gc-TSEB model was recalibrated with the changed inputs.

Compared with Gc-TSEB, PT-TSEB showed less robustness at the crop site; the RMSEs and biases were not well constrained with varying LAI (Fig. 5). However, both models were found to be quite robust by the recalibration sensitivity tests. In the recalibration cases, Gc-TSEB also showed robustness in partitioning $L E$ into $L_{c}$ and $\mathrm{LE}_{\mathrm{S}}$ at both sites (Fig. 6), and PT-TSEB showed similar robustness at the grass site. Although it was less robust than Gc-TSEB at the crop site, especially when the LAI was decreased by $30 \%$ and when the soil moisture content was decreased by 40\%, PT-TSEB performed quite well with changes of $\pm 20 \%$ in both inputs.

The sensitivity tests presented above indicated that the models would perform reasonably well even with flawed input data if only the error of the model-predicted LST is minimized. The resistance network would automatically adapt to the change in the input data. The maximum stomatal conductance or $\alpha_{\mathrm{PT}}$ would increase to compensate for the effect of the decreased LAI on the canopy conductance and vice versa. Similarly, when the near surface soil 

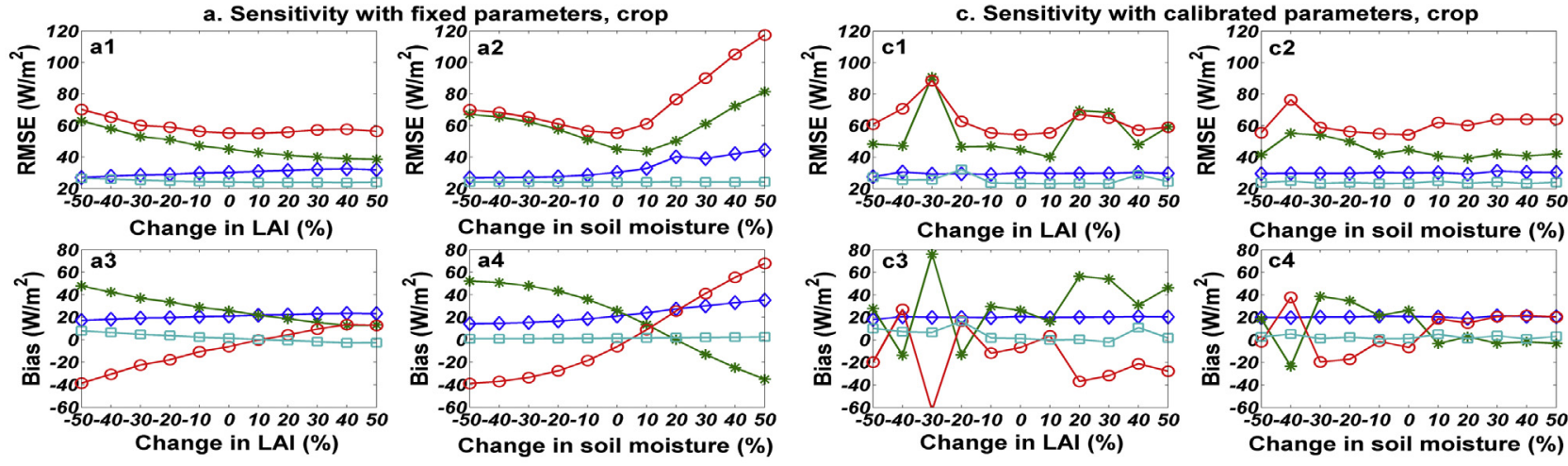

b. Sensitivity with fixed parameters, grass


Change in soil moisture $(\%)$

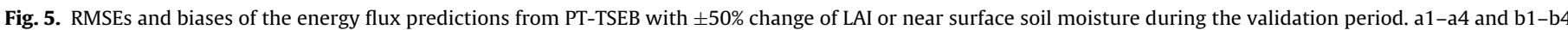

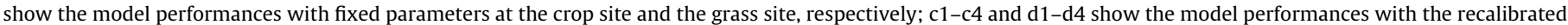
parameters at the crop site and the grass site, respectively.
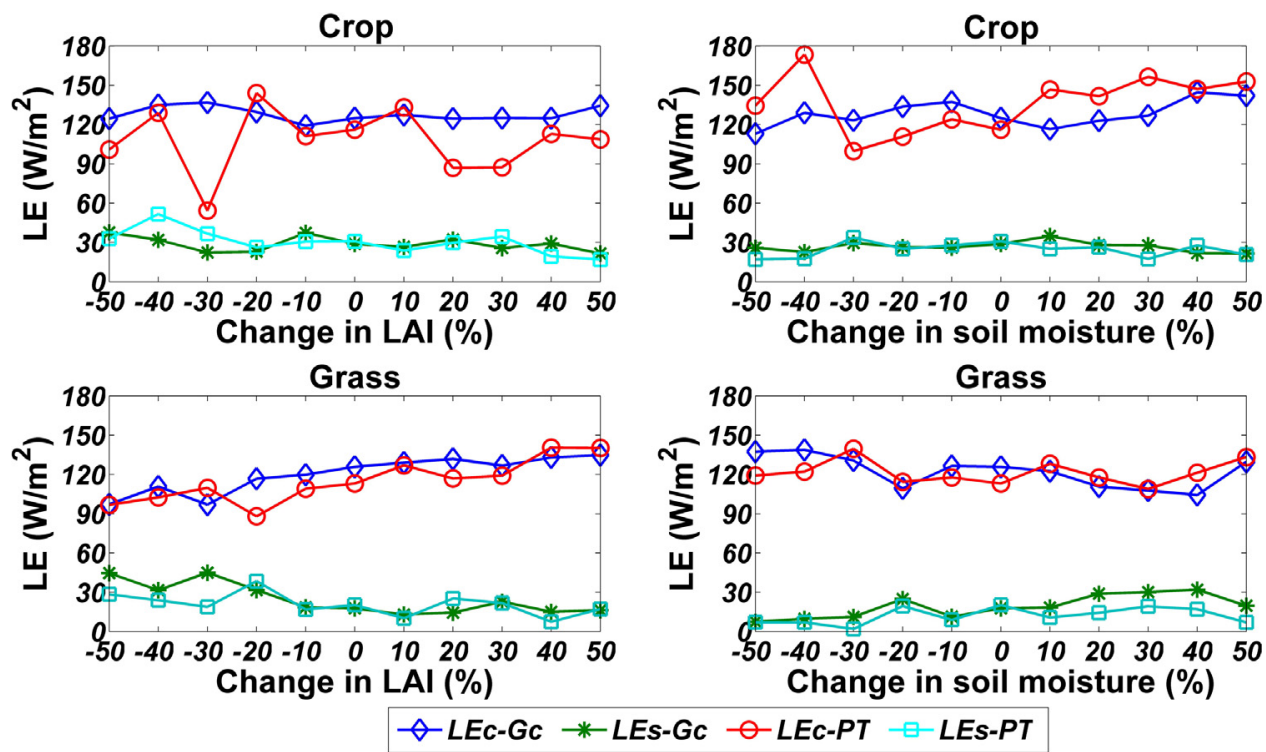

Fig. 6. LE partitioning from both models with $\pm 50 \%$ changes of LAI or near surface soil moisture during the validation period.

moisture was decreased, the resistance of the surface soil to water vapor would also decrease by reducing the difference between the two coefficients of $r_{\mathrm{ss}}$; that is, $a_{0}-a_{1}$ and vice versa.

The robustness of the two models, especially Gc-TSEB, is of great practical use because the model inputs, especially the near surface soil moisture, may be biased systematically by measurement errors and scale effects. Although the near surface soil moisture is highly variable in both space and time, its spatial patterns tend to persist over time, which is known as the temporal stability (Vachaud et al., 1985). As a result, soil moisture contents from in-situ measurements, passive microwave remote sensing, or soil moisture balance models (Yan et al., 2012) are often highly correlated with those at MODIS scales, in which case the model performances are guaranteed by the robustness of both models.

Because the model robustness depends on the accuracy of the LST, the impacts of LST errors on the model performances were also 

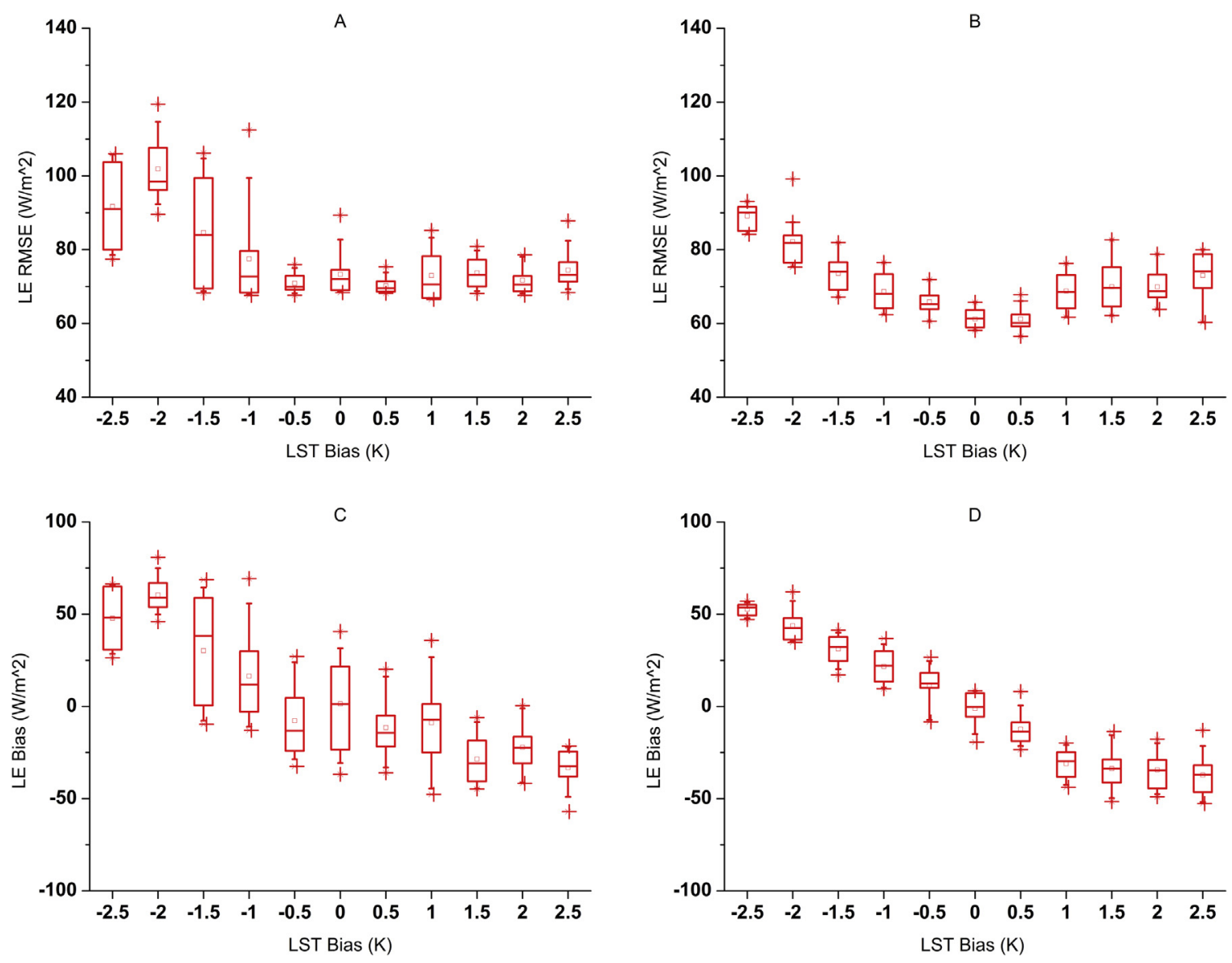

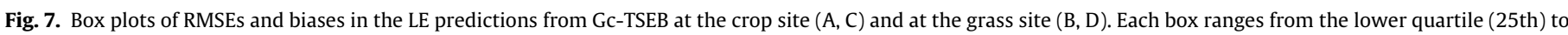
the upper quartile (75th). The median is represented by the middle line in the box. The plus signs represent the points beyond the whiskers.

analyzed. We progressively added increasing amounts of noises that followed the Gaussian distribution $\mathrm{N}\left(\mu, \sigma^{2}\right)$, where $\sigma=2.5 \mathrm{~K}$, and $\mu=0, \pm 0.5, \pm 1, \pm 1.5, \pm 2$, and $\pm 2.5 \mathrm{~K}$, to the original LST signal and then re-calibrated the models with the original inputs. For each pair of $(\mu, \sigma)$, we calibrated and ran models ten times; each time used a new set of LST signals.

Overall, the models are quite sensitive to the mean biases of the LST. Box plots of the LE prediction performance (Figs. 7 and 8) show that the medians of both the RMSEs and the absolute values of the biases in LE increased with $|\mu|$. Each box could cover a wide range even when $|\mu|$ was small because the noise we added to the LST signal was random, which means that even with $\mu=0$, there is still a chance that the mean of the added noise is much larger or smaller than 0 . If the LST is systematically biased, it is no longer as effective as the flux measurements in calibrating models (compared to Table 3). However, LST calibration is still valuable for improving the model performance. We found that both models that were calibrated by the noise-affected LST performed better than the non-calibrated PT-TSEB; they usually had smaller RMSEs and absolute values of the biases even when the mean bias of the LST reached $\pm 2.5 \mathrm{~K}$ with a standard deviation of $2.5 \mathrm{~K}$ (Table 3 and Figs. 7 and 8 ). In addition, when $|\mu|$ was less than $1 \mathrm{~K}$, the medians of the RMSEs from both models, especially from Gc-TSEB, were similar to those from the models that were calibrated by flux measurements.

Independent evaluations of the Version 5 MODIS LST at more than 40 sites, including lake, snow, urban, crop, grass, and forest sites, showed that under clear-sky conditions, the means and standard deviations (STDs) of the LST errors are usually within $1 \mathrm{~K}$ (within $2 \mathrm{~K}$ in all cases) (Coll et al., 2009; Wan and Li, 2008; Wan, 2014). However, large LST errors (mean bias $=-2.79 \mathrm{~K}$ and
$\mathrm{STD}=2.52 \mathrm{~K}$ ) at bare soil sites in arid regions have also been reported (Li et al., 2014). Therefore, caution should be taken if the calibration dataset mainly consists of data from low vegetation periods.

\subsection{Evaluations of day-to-day and diurnal flux predictions}

LE at daytime scales and its diurnal variations are useful in many water related applications, such as irrigation scheduling and watershed water resource managements. We aggregated LE predictions from the LST-calibrated GC-TSEB and PT-TSEB models to daytime scales. Overall, the daytime predictions matched the trends of the EC measurements well and greatly outperformed those from the non-calibrated PT-TSEB model at both sites (Fig. 9). Although precipitation was not incorporated directly in the Gc-TSEB and PT-TSEB models, both models' LE predictions showed clear trends and peaks that were usually related to precipitation events.

In contrast, although the PM-Mu model demands fewer inputs (wind speed, soil moisture) and is easier to use (no iteration procedures are needed), using it with the default biome-specific parameters from Mu et al.'s paper (2011) performed not as well as the LST-calibrated Gc-TSEB and PT-TSEB models (Table 5) and was unable to simulate the LE trends at both sites on a day-to-day basis (Fig. 9). Note that this comparison is not intended to deny the rationality or the applicability of the PM-Mu model at global scales. In addition, like TSEB schemes, Gc-PM models have the ability to incorporate surface soil moisture data to implicitly reflect the controlling effect of precipitation on LE (Sun et al., 2013). However, unlike Gc-TSEB and PT-TSEB, it is difficult to link LST to Gc-PM models because the PM equation results from the elimination of LST in 

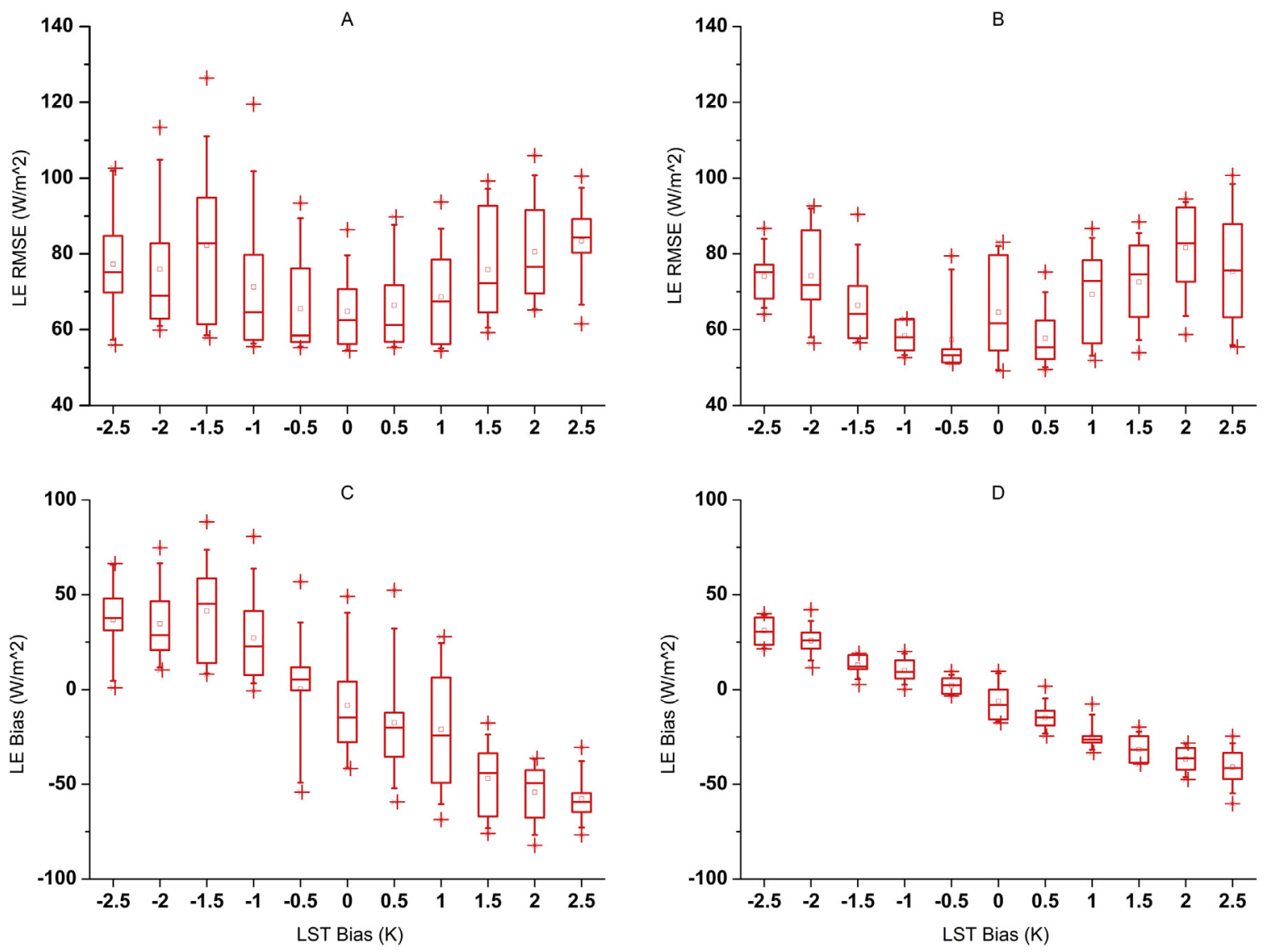

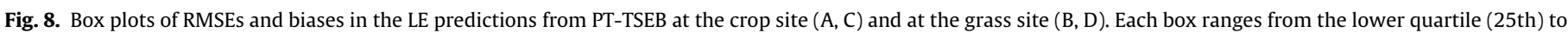
the upper quartile (75th). The median is represented by the middle line in the box. The plus signs represent the points beyond the whiskers.
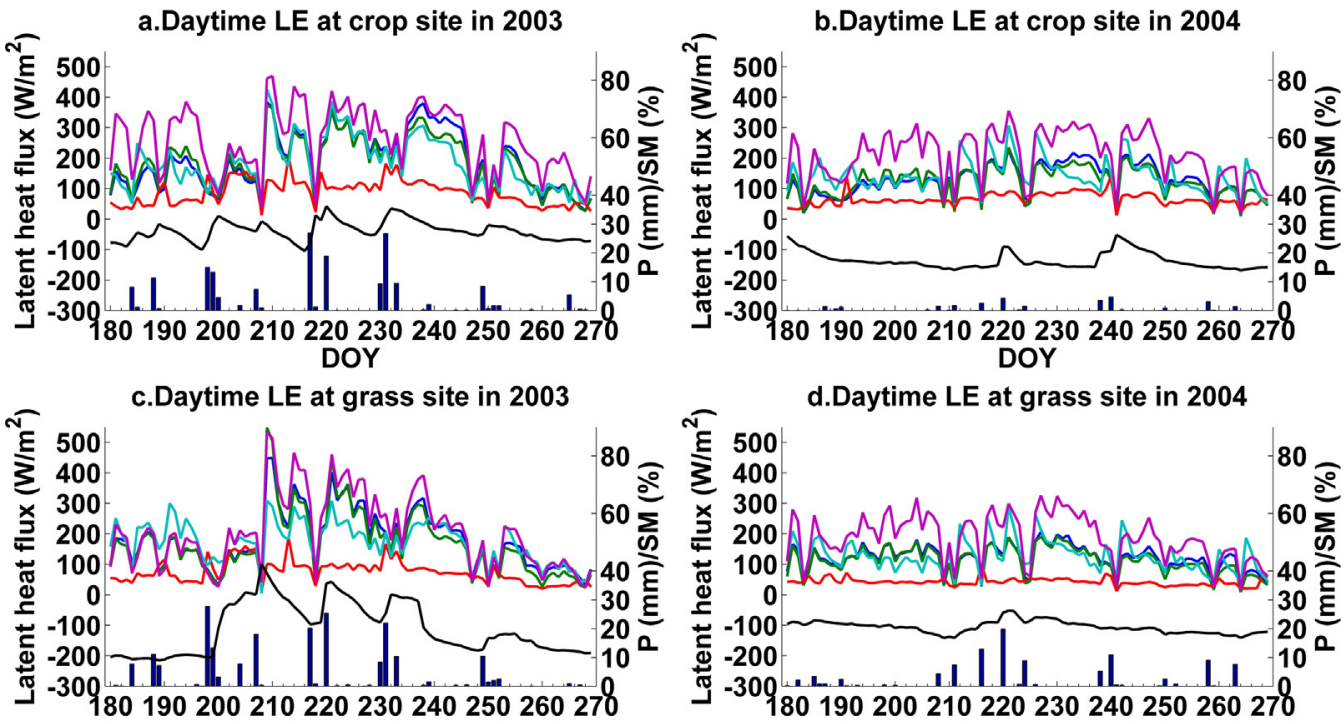

Precipitation - Soil moisture - Gc-TSEB — PT-TSEB — PM-Mu - EC-flux — PT-TSEB-NC

Fig. 9. Daytime LE predictions from the Gc-TSEB, PT-TSEB, PM-Mu, and non-calibrated PT-TSEB (PT-TSEB-NC) models.

the surface energy balance equation (Zhan and Kustas, 2001). As a result, the reliance on in-situ measurements in pixel-wise calibrations may be an obstacle to Gc-PM type models, especially when the models are applied to mixed pixels.

However, it should be noted that despite providing overall good performance, Gc-TSEB and PT-TSEB models that are calibrated by
LST may produce systematically biased predictions due to the decoupling effect of soil moisture at different depths (Capehart and Carlson, 1997) and the fact that the soil surface energy balance is more strongly coupled to the surface moisture conditions than at deeper layers (Kustas et al., 2003). For example, light precipitation events (e.g., less than $12 \mathrm{~mm}$ ) that moistened the 
Table 5

RMSEs and biases of the daytime predictions of $R_{\mathrm{n}}$ and LE.

\begin{tabular}{|c|c|c|c|c|c|}
\hline & & \multicolumn{2}{|l|}{$R_{\mathrm{n}}$} & \multicolumn{2}{|l|}{ LE } \\
\hline & & $\begin{array}{l}\text { Bias } \\
\left(\mathrm{W} / \mathrm{m}^{2}\right)\end{array}$ & $\begin{array}{l}\text { RMSE } \\
\left(\mathrm{W} / \mathrm{m}^{2}\right)\end{array}$ & $\begin{array}{l}\text { Bias } \\
\left(\mathrm{W} / \mathrm{m}^{2}\right)\end{array}$ & $\begin{array}{l}\text { RMSE } \\
\left(\mathrm{W} / \mathrm{m}^{2}\right)\end{array}$ \\
\hline \multirow[t]{4}{*}{ Crop } & Gc-TSEB & 13.62 & 47.16 & 1.39 & 48.65 \\
\hline & PT-TSEB & 20.91 & 47.99 & -6.66 & 42.14 \\
\hline & Gs-PM & 65.4 & 87.44 & -66.3 & 85.07 \\
\hline & Gc-TSEB & 10.47 & 46.03 & -5.84 & 52.35 \\
\hline \multirow[t]{2}{*}{ Grass } & PT-TSEB & 40.19 & 59.64 & -8.62 & 54.73 \\
\hline & Gs-PM & 63.33 & 84.85 & -71.57 & 85.87 \\
\hline
\end{tabular}

soil surface sometimes hardly increased the soil moisture at a depth of $0.05 \mathrm{~m}$, especially when the soil moisture content was low (e.g., DOY 184-195 in 2003 at the grass site); thus, both models underestimated LE by approximately $60 \mathrm{~W} / \mathrm{m}^{2}$ during that period. In addition, positive biases (Gc-TSEB: $84.8 \mathrm{~W} / \mathrm{m}^{2}$; PT-TSEB: $96.2 \mathrm{~W} / \mathrm{m}^{2}$ ) were found during some of the dry soil periods, such as DOY 209-216 in 2003 at the grass site, which indicates that the soil above $0.05 \mathrm{~m}$ dried much faster than the soil at $0.05 \mathrm{~m}$.
To address this problem, we tried Lee and Pielke's general formulation (1992) of the soil surface relative humidity to estimate soil evaporation. Similar results of LE were produced, but no improvements in the LE estimates were found. This indicated that to improve estimates of soil evaporation, a new parameterization other than the heat transfer equation may be needed under soil moisture decoupling conditions.

To gain deeper insight into the dynamics of the Gc-TSEB and PT-TSEB models (calibrated by LST), we evaluated the models' diurnal performances at both sites during the period from DOY 195 to DOY 203 in 2003. In the middle of this period, precipitation occurred for three continuous days (DOY 198-200; $15.1 \mathrm{~mm}$, $13.4 \mathrm{~mm}$, and $4.6 \mathrm{~mm}$, respectively, at the crop site and $27.8 \mathrm{~mm}$, $13.3 \mathrm{~mm}$, and $3.2 \mathrm{~mm}$, respectively, at the grass site) (Fig. 9). The modeled LE matched the trends and magnitudes of the EC measurements well at the crop site but missed the peak on DOY 199 and failed to match the diurnal cycle on DOY 200 because of the daytime precipitation (Fig. 10). At the grass site, both Gc-TSEB and PT-TSEB produced similar LE trends to the EC measurements but underestimated LE by approximately $44.7 \mathrm{~W} / \mathrm{m}^{2}$ (Gc-TSEB) and $49.3 \mathrm{~W} / \mathrm{m}^{2}$ (PT-TSEB) because of the decoupling



b.Diurnal LE at grass site

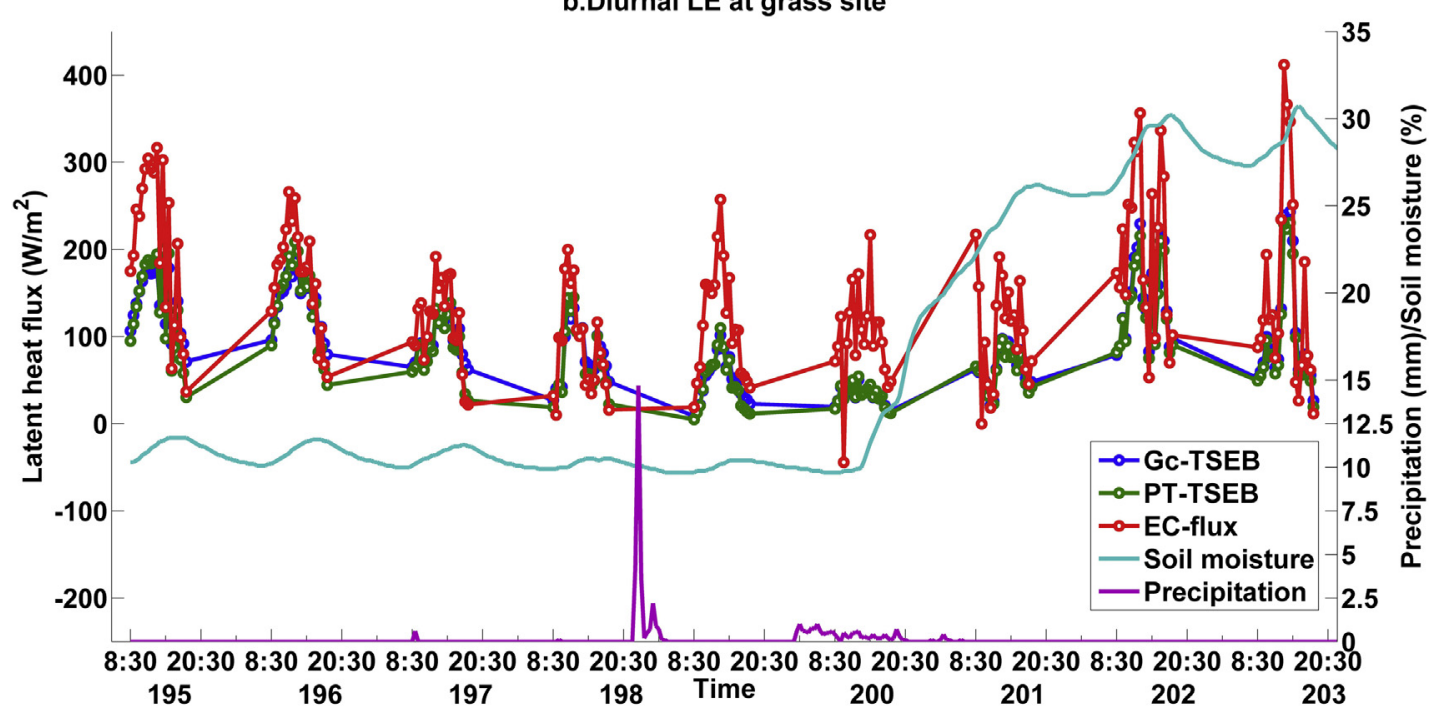

Fig. 10. Diurnal LE predictions from Gc-TSEB and PT-TSEB from DOY 195 to 203. 

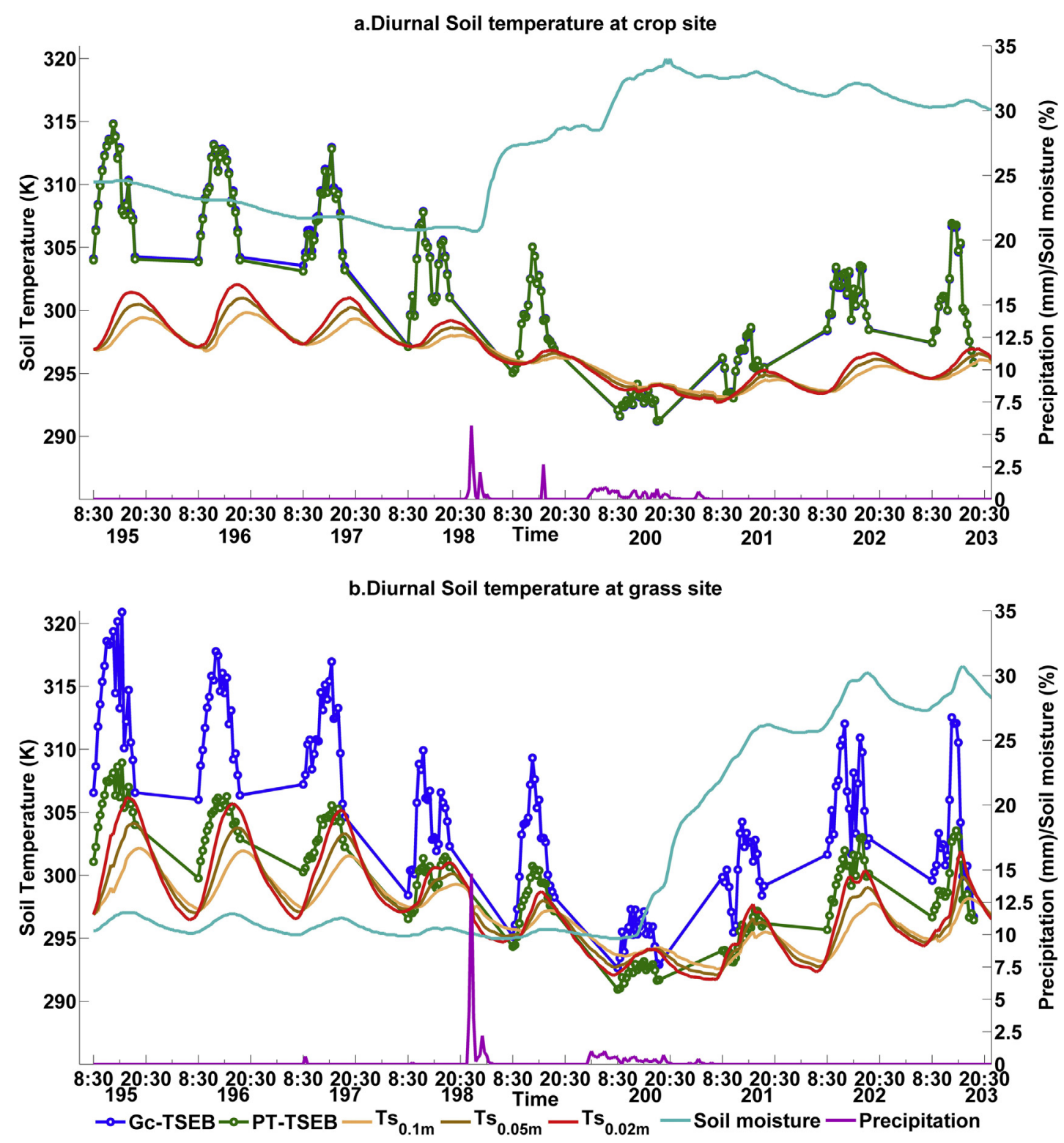

Fig. 11. Diurnal soil temperatures at different depths from DOY 195 to 203.

of the soil moisture content at the surface and at deeper layers.

The soil surface temperatures $\left(T_{\mathrm{S}}\right)$ from Gc-TSEB and PT-TSEB models vary in a consistent diurnal pattern with the measured soil temperatures at depths of $0.1 \mathrm{~m}, 0.05 \mathrm{~m}$, and $0.02 \mathrm{~m}$ but with a phase shift ahead (Fig. 11). The direct evaluation of $T_{\mathrm{S}}$ is difficult because of the scale and depth differences between the modeled and measured values. However, the $\sim 20 \mathrm{~W} / \mathrm{m}^{2}$ bias of the $R_{\mathrm{n}}$ estimation when using remotely sensed LST during the calibration period indicates that the LST estimations from Gc-TSEB and PTTSEB at the crop site and those from Gc-TSEB at the grass site were reasonable because the corresponding $R_{\mathrm{n}}$ biases were also approximately $20 \mathrm{~W} / \mathrm{m}^{2}$ during the validation periods (Table 3 ). As a result, the overestimation of $R_{\mathrm{n}}\left(\sim 40 \mathrm{~W} / \mathrm{m}^{2}\right)$ from PT-TSEB at the grass site (Table 3 ) indicated that the LST had been underestimated in this case. This underestimation may result from the smaller amount of coupling between the canopy temperature and the canopy fluxes in the PT-TSEB model than that in the Gc-TSEB model.

\section{Conclusions}

In this study, we incorporated a canopy conductance model into TSEB $_{S M}$ to replace the original PT approximation and updated the formulation of the under-canopy resistance. We then optimized both models (the Gc version and the PT version) at pixel scales using qualified remotely sensed LST. The LE and its partitioning between the canopy and soil layers were found to be reasonable at both validation sites. In addition, LST was shown to be almost as effective as flux measurements in calibrating the models. The resistance networks of the Gc-TSEB and PT-TSEB models are adjustable, so they are not sensitive to the uncertainties of the LAI and the near surface soil moisture. As a result, the advantages of remotely sensed LST, such as their spatial continuity and their greater availability compared to flux measurements, allow the wide use of Gc-TSEB and PT-TSEB in energy flux estimations. Cloud contamination in LST images is no longer an impediment to remote sensing ET models because LST is only used in calibration instead of prediction. 
The day-to-day and diurnal variations of the predicted LE matched the trends and peaks of the EC measurements well, although systematic biases were found due to the decoupling effect of soil moisture at different depths. In addition, systematic biases of LST may result in systematically biased flux predictions by overcalibrating the models. However, if the mean bias of LST is bounded by $\pm 1 \mathrm{~K}$ (STD of $2.5 \mathrm{~K}$ ), the medians of the RMSEs in the LE predictions from the LST-calibrated models were found to be similar to those from the flux-calibrated models.

Overall, the time series of the calculated energy fluxes at the two sites of Tongyu station showed that the canopy conductance was successfully incorporated into the resistance network. More validations are needed at flux observation sites with various land cover types around the world to test the usefulness of the models as a routine method. Furthermore, improvements of the parameterization of the heat/vapor transfer resistances should also be included in the TSEB framework in the future, especially those that are concerned with soil evaporation.

\section{Acknowledgements}

Our research is funded by the National Key Project for Basic Research (973) (No. 2015CB452705), the Key Project of National Natural Science Foundation of China (No. 41430861), and the National Natural Science Foundation of China (No. 40871198). The MODIS data were downloaded from the NASA Goddard Space Flight Center (http://ladsweb.nascom.nasa.gov/data/). The CEOP/EOP-3 and CEOP/EOP-4 data (http://www.ceop.net/) were collected and provided by the "Predictive Study of Aridification in Northern China in association with Life-supporting Environment Changes" projects, which was funded by the National Key Basic Research Development Program G1999043404.

We would like to thank both anonymous reviewers for their helpful comments and Prof. Renjian Zhang of the Institute of Atmospheric Physics, Chinese Academy of Sciences, for his assistance in interpreting the CEOP data. We thank Maofeng Liu and Jinfeng Wang for their help with the manuscript revisions.

\section{References}

Anderson, M.C., Norman, J.M., Diak, G.R., Kustas, W.P., Mecikalski, J.R., 1997. A two-source time-integrated model for estimating surface fluxes using thermal infrared remote sensing. Remote Sens. Environ. 60 (2), 195-216.

Anderson, M.C., et al., 2008. A thermal-based remote sensing technique for routine mapping of land-surface carbon, water and energy fluxes from field to regional scales. Remote Sens. Environ. 112 (12), 4227-4241.

Anderson, M.C., Norman, J.M., Meyers, T.P., Diak, G.R., 2000. An analytical model for estimating canopy transpiration and carbon assimilation fluxes based on canopy light-use efficiency. Agric. For. Meteorol. 101 (4), 265-289.

Boegh, E., Soegaard, H., Thomsen, A., 2002. Evaluating evapotranspiration rates and surface conditions using Landsat TM to estimate atmospheric resistance and surface resistance. Remote Sens. Environ. 79 (2-3), 329-343.

Camillo, P.J., Gurney, R.J., 1986. A resistance parameter for bare-soil evaporation models. Soil Sci. 141 (2), 95-105

Capehart, W.J., Carlson, T.N., 1997. Decoupling of surface and near-surface soil water content: a remote sensing perspective. Water Resour. Res. 33 (6), 1383-1395.

Cleugh, H.A., Leuning, R., Mu, Q.Z., Running, S.W., 2007. Regional evaporation estimates from flux tower and MODIS satellite data. Remote Sens. Environ. 106 (3), 285-304

Colaizzi, P.D., et al., 2012. Two-source energy balance model estimates of evapotranspiration using component and composite surface temperatures. Adv. Water Resour. 50, 134-151.

Coll, C., Wan, Z.M., Galve, J.M., 2009. Temperature-based and radiance-based validations of the V5 MODIS land surface temperature product. J. Geophys. Res. Atmos., 114.

Dekkers, A., Aarts, E., 1991. Global optimization and simulated annealing. Math. Program. 50 (3), 367-393.

French, A.N., et al., 2005. Surface energy fluxes with the advanced spaceborne thermal emission and reflection radiometer (ASTER) at the Iowa 2002 SMACEX site (USA) (vol 99, pg 55, 2005). Remote Sens. Environ. 99 (4), 471.

Gao, Y.C., Long, D., 2008. Intercomparison of remote sensing-based models for estimation of evapotranspiration and accuracy assessment based on SWAT. Hydrol. Process. 22 (25), 4850-4869.
Heusinkveld, B.G., Jacobs, A.F.G., Holtslag, A.A.M., Berkowicz, S.M., 2004. Surface energy balance closure in an arid region: role of soil heat flux. Agric. For. Meteorol. 122 (1-2), 21-37.

Kirkpatrick, S., Gelatt, C.D., Vecchi, M.P., 1983. Optimization by simulated annealing. Science 220 (4598), 671-680.

Kool, D., et al., 2014. A review of approaches for evapotranspiration partitioning. Agric. For. Meteorol. 184, 56-70.

Kustas, W.P., Bindlish, R., French, A.N., Schmugge, T.J., 2003. Comparison of energy balance modeling schemes using microwave-derived soil moisture and radiometric surface temperature. Water Resour. Res. 39 (2).

Kustas, W.P., Jackson, T.J., French, A.N., MacPherson, J.I., 2001. Verification of patchand regional-scale energy balance estimates derived from microwave and optical remote sensing during SGP97. J. Hydrometeorol. 2 (3), 254-273.

Kustas, W.P., Norman, J.M., 1999. Evaluation of soil and vegetation heat flux predictions using a simple two-source model with radiometric temperatures for partial canopy cover. Agric. For. Meteorol. 94 (1), 13-29.

Kustas, W.P., Zhan, X., Schmugge, T.J., 1998. Combining optical and microwave remote sensing for mapping energy fluxes in a semiarid watershed. Remote Sens. Environ. 64 (2), 116-131.

Kustas, W.P., Zhan, X.W., Jackson, T.J., 1999. Mapping surface energy flux partitioning at large scales with optical and microwave remote sensing data from Washita ‘92. Water Resour. Res. 35 (1), 265-277.

Lee, T.J., Pielke, R.A., 1992. Estimating the soil surface specific-humidity. J. Appl. Meteorol. 31 (5), 480-484.

Leuning, R., Zhang, Y.Q., Rajaud, A., Cleugh, H., Tu, K., 2008. A simple surface conductance model to estimate regional evaporation using MODIS leaf area index and the Penman-Monteith equation. Water Resour. Res. 44 (10).

Li, F.Q., et al., 2006. Comparing the utility of microwave and thermal remote-sensing constraints in two-source energy balance modeling over an agricultural landscape. Remote Sens. Environ. 101 (3), 315-328.

Li, F.Q., Kustas, W.P., Prueger, J.H., Neale, C.M.U., Jackson, T.J., 2005. Utility of remote sensing-based two-source energy balance model under low- and high-vegetation cover conditions. J. Hydrometeorol. 6 (6), 878-891.

Li, H., et al., 2014. Evaluation of the VIIRS and MODIS LST products in an arid area of northwest China. Remote Sens. Environ. 142, 111-121.

Liu, M.F., 2012. Estimation of annual evapotranspiration of baiyangdian watershed using remotely sensed data. In: Master Thesis. Graduate University of Chinese Academy of Science.

Long, D., Singh, V.P., 2010. Integration of the GG model with SEBAL to produce time series of evapotranspiration of high spatial resolution at watershed scales. J. Geophys. Res. Atmos., 115.

McCabe, M.F., Wood, E.F., 2006. Scale influences on the remote estimation of evapotranspiration using multiple satellite sensors. Remote Sens. Environ. 105 (4), 271-285.

Monteith, J.L., 1965. Evaporation and environment. Symp. Soc. Exp. Biol. 19, 205-234.

Mu, Q., Heinsch, F.A., Zhao, M., Running, S.W., 2007. Development of a global evapotranspiration algorithm based on MODIS and global meteorology data. Remote Sens. Environ. 111 (4), 519-536.

Mu, Q.Z., Zhao, M.S., Running, S.W., 2011. Improvements to a MODIS global terrestrial evapotranspiration algorithm. Remote Sens. Environ. 115 (8), $1781-1800$.

Norman, J.M., Kustas, W.P., Humes, K.S., 1995. Source approach for estimating soil and vegetation energy fluxes in observations of directional radiometric surface-temperature. Agric. For. Meteorol. 77 (3-4), 263-293.

Norman, J.M., Kustas, W.P., Prueger, J.H., Diak, G.R., 2000. Surface flux estimation using radiometric temperature: a dual temperature-difference method to minimize measurement errors. Water Resour. Res. 36 (8), 2263-2274.

Oki, T., Kanae, S., 2006. Global hydrological cycles and world water resources. Science 313 (5790), 1068-1072.

Oleson, K., et al. 2010. Technical Description of version 4.0 of the Community Land Model (CLM). NCAR Technical Note NCAR/TN-478+STR.

Penman, H.L., 1948. Natural evaporation from open water, bare soil and grass. Proc R. Soc. Lond. Ser. A 193 (1032), 120.

Priestley, C.H.B., Taylor, R.J., 1972. Assessment of surface heat-flux and evaporation using large-scale parameters. Mon. Weather Rev. 100 (2), 81

Sanchez, J.M., Kustas, W.P., Caselles, V., Anderson, M.C., 2008. Modelling surface energy fluxes over maize using a two-source patch model and radiometric soil and canopy temperature observations. Remote Sens. Environ. 112 (3), 1130-1143.

Sellers, P.J., Heiser, M.D., Hall, F.G., 1992. Relations between surface conductance and spectral vegetation indexes at intermediate $\left(100 \mathrm{~m}^{2}\right.$ to $\left.15 \mathrm{~km}^{2}\right)$ length scales. J. Geophys. Res. Atmos. 97 (D17), 19033-19059.

Sun, L., Liang, S.L., Yuan, W.P., Chen, Z.X., 2013. Improving a Penman-Monteith evapotranspiration model by incorporating soil moisture control on soil evaporation in semiarid areas. Int. J. Digital Earth 6, 134-156.

Timmermans, W.J., Kustas, W.P., Anderson, M.C., French, A.N., 2007. An intercomparison of the surface energy balance algorithm for land (SEBAL) and the two-source energy balance (TSEB) modeling schemes. Remote Sens. Environ. 108 (4), 369-384.

Trenberth, K.E., Fasullo, J.T., Kiehl, J., 2009. Earth's global energy budget. Bull. Am. Meteorol. Soc. 90 (3), 311

Trenberth, K.E., Smith, L., Qian, T.T., Dai, A., Fasullo, J., 2007. Estimates of the global water budget and its annual cycle using observational and model data. J. Hydrometeorol. 8 (4), 758-769. 
Tu, G., 2007. Study on land-atmosphere interaction on different underlying surface of semi arid region. In: Ph.D Thesis. Graduate University of Chinese Academy of Science.

Twine, T.E., et al., 2000. Correcting eddy-covariance flux underestimates over a grassland. Agric. For. Meteorol. 103 (3), 279-300.

Vachaud, G., Desilans, A.P., Balabanis, P., Vauclin, M., 1985. Temporal stability of spatially measured soil-water probability density-function. Soil Sci. Soc. Am. J. 49 (4), 822-828

Wan, Z., Li, Z.L., 2008. Radiance-based validation of the V5 MODIS land-surface temperature product. Int. J. Remote Sens. 29 (17-18), 5373-5395.

Wan, Z.M., 2014. New refinements and validation of the collection-6 MODIS land-surface temperature/emissivity product. Remote Sens. Environ. 140, 36-45.
Yan, H., et al., 2012. Global estimation of evapotranspiration using a leaf area index-based surface energy and water balance model. Remote Sens. Environ. $124,581-595$.

Zeng, X.B., et al., 2005. Treatment of undercanopy turbulence in land models. J. Clim. 18 (23), 5086-5094.

Zhan, X., Kustas, W.P., 2001. A coupled model of land surface $\mathrm{CO}_{2}$ and energy fluxes using remote sensing data. Agric. For. Meteorol. 107 (2), 131-152.

Zhang, Y.Q., Chiew, F.H.S., Zhang, L., Leuning, R., Cleugh, H.A., 2008. Estimating catchment evaporation and runoff using MODIS leaf area index and the Penman-Monteith equation. Water Resour. Res. 44 (10).

Zhang, Y.Q., et al., 2010. Using long-term water balances to parameterize surface conductances and calculate evaporation at 0.05 degrees spatial resolution. Water Resour. Res., 46. 